\title{
Microhabitats of sharknose goby (Elacatinus evelynae) cleaning stations and their links with cleaning behaviour
}

\author{
Kathryn E. Whittey ${ }^{1,2}$ (1) $\cdot$ Katie Dunkley ${ }^{1,3} \cdot$ Grace C. Young $^{2} \cdot$ Jo Cable $^{1} \cdot$ \\ Sarah E. Perkins ${ }^{1}$
}

Received: 21 April 2020/ Accepted: 19 April 2021/Published online: 3 May 2021

(C) The Author(s) 2021

\begin{abstract}
Coral reefs are renowned for the complexity of their habitat structures and their resulting ability to host more species per unit area than any another marine ecosystem. Dedicated cleaner fish, which acquire all their food resources through client interactions, rely on both the habitat structures (by using topological cleaning stations) and the wide diversity of fish species available on coral reefs, to function. As a result of natural and anthropogenic threats, coral reef habitat structures and their complexity are being lost-despite this threat it is unclear how important reef geometry is to key ecological interactions, like cleaning. Using an established Caribbean reef study site, threedimensional constructions of discrete coral heads were used to investigate how fine-scale structural complexity traits (structural complexity-measured by rugosity and vector dispersion-height, volume, surface area, percentage live coral cover and refuge availability) relate to cleaner occupancy, abundance and their cleaning interactions with clients. Coral height was a particularly important trait for
\end{abstract}

Kathryn E. Whittey, Katie Dunkley are Joint First Authors

Jo Cable, Sarah E. Perkins are Joint Senior Authors

Topic Editor Stuart Sandin

Kathryn E. Whittey

WhitteyKE@Cardiff.ac.uk;

https://www.cardiff.ac.uk/people/research-students/view/

1149829-whittey-kathryn

1 School of Biosciences, Cardiff University, Cardiff CF10 3AX, UK

2 Hydrous, PO Box 309, Sausalito 94966, CA, USA

3 Department of Zoology, University of Cambridge, Cambridge CB2 3EJ, UK cleaning, correlating with both the occurrence of cleaning stations on a reef, and with increased cleaning durations and reduced cleaning frequencies/rates. Cleaning stations were also more structurally complex than non-cleaning coral heads, and the increased availability of uneven surfaces (creating cracks and crevices) and refuge availability linked with increased cleaning durations/rates. By understanding habitat features important to cleaner fish on a typical Caribbean fringing reef, we can gain a better understanding of how important reef geometry might be for governing the occurrence and dynamics of such mutualisms.

Keywords Cleaner fish - Elacatinus evelynae . Mutualism · Photogrammetry - Structural complexity · Three-dimensional modelling

\section{Introduction}

Coral reefs are renowned for their complex physical threedimensional structure (termed structural complexity; Graham and Nash 2013). Scleractinia stony corals, which produce hard exoskeletons, are ecosystem engineers, and are largely responsible for the structural complexity of coral reefs (Jones et al. 1994; Wild et al. 2011). Corals' high structural complexity creates a plethora of different microhabitats (Crowder and Cooper 1982), ultimately creating one of the most diverse and abundant habitats in the world (on par with rainforests; Reaka-Kudla 1997). Within a reef environment, different microhabitats influence the spatial distribution of species (Tolimieri 1995) since many species show specific microhabitat preferences (Booth and Wellington 1998; Majoris et al. 2018a), exhibit high site fidelity (Streit and Bellwood 2018) and form close associations with certain microhabitat types (Boström- 
Einarsson et al. 2018). However, finer scale variations in coral morphology (e.g. height and substrate heterogeneity) may also promote finer scale differences in species spatial distributions as a result of altered microhabitat-a concept which so far has received little attention in coral reef literature. Since coral structural complexity is under threat from anthropogenic climate change and industrialism (Munday 2004), it is vital to determine the importance of small-scale variation in coral morphology for reef species.

Structural complexity can influence the outcomes of ecological interactions (e.g. predation; Crowder and Cooper 1982; Grabowski 2004, competition; Petren and Case 1998, and herbivory; Vergés et al. 2011), with the magnitude of the effect potentially varying with the degree of complexity (Grabowski 2004). This hypothesis is intriguing and may help further our understanding of the dynamic nature of a classic mutualistic relationship; cleaner-client interactions, which are ubiquitous on coral reefs (White et al. 2007). Cleaning involves a cleaner removing parasites and debris from the body of another species, termed a client (Feder 1966). Dedicated cleaner fish gain all their nutrition from client derived material (formerly termed obligate; Vaughan et al. 2017) and associate strongly with cleaning stations. Cleaners wait at their cleaning stations for clients to visit them, and it has been shown that associating with a cleaning station, rather than wandering across a reef, promotes increased cleaning interactions (Oates et al. 2010; Dunkley et al. 2018). Despite a wealth of knowledge on the ecology of cleanerclient interactions, microhabitat characteristics of cleaning stations are poorly defined. Stations can be cryptic and have been referred to as 'particular ecological situations' (Limbaugh 1961; Youngbluth 1968), which may include corals, anemones or sponges, collection of rocks, and or depressions in the benthos (Limbaugh 1961; Losey 1974; Johnson and Ruben 1988; Sazima et al. 1999; Cheney and Côté 2001; Huebner and Chadwick 2012). Since substrate type can influence the frequency and duration of cleaning interactions (e.g. coral versus sponge; Whiteman and Côté 2002), in addition to the fine-scale distribution, movement, density and diversity of potential clients (Ferreira et al. 2001; Graham and Nash 2013; Ferrari et al. 2018), localised variation in coral morphology may also be expected to influence localised variations in cleaning dynamics.

Traditional methods for quantifying structural complexity, like the chain/tape transect method and Habitat Assessment Scores (Gratwicke and Speight 2005; Wilson et al. 2007) are now being replaced by digital three-dimensional modelling. Such modelling allows for the in silico quantification of habitat complexity traits (e.g. substrate heterogeneity, measured as rugosity and vector dispersion; Storlazzi et al. 2016; González-Rivero et al. 2017; Young et al. 2017, volume and surface area; Ferrari et al.
2017; Raoult et al. 2017, coral cover; González-Rivero et al. 2017, and coral growth; Lange and Perry 2020), which provides finer scale measurements for addressing ecological questions (Storlazzi et al. 2016). Indeed, these techniques have already advanced our understanding on the relationships between varying structural complexity traits and reef fish assemblages (Price et al. 2019) and identified microhabitat types that promote invasive lionfish (Pterois volitans) aggregations in the Caribbean (Hunt et al. 2019). The high resolution of such techniques will facilitate the quantification of finer scale variations in coral morphology within a reef environment.

Here, we investigated how different coral morphologies of Faviidae corals, a common group of Caribbean corals, promote variation in the occupancy and cleaning patterns of the predominant dedicated Caribbean cleaner, the sharknose goby (Elacatinus evelynae). Using a structure-frommotion approach (Reichert et al. 2016; Ferrari et al. 2017; Young et al. 2017), we constructed three-dimensional models of discrete Faviidae coral heads on a reef in Tobago and quantified different microhabitat traits (e.g. rugosity, height and volume). We then determined whether these different traits distinguished coral heads utilised as cleaning stations versus those that have never been observed as cleaning stations across 8 years of long-term study (see Dunkley et al. 2019b). Subsequently, for cleaning station coral heads, we tested the hypotheses that microhabitat features link to cleaner occupancy distributions and cleaning behaviours (in terms of frequencies, durations and rates). Together, this study aimed to quantify what microhabitat features may define (or not) a cleaning station.

\section{Materials and methods}

\section{Study site, occupancy and behavioural observations}

The study was conducted on Booby Reef in Man O' War Bay, Tobago $\left(11^{\circ} 19.344^{\prime} \mathrm{N}, 060^{\circ} 33.484^{\prime} \mathrm{W}\right)$. The site constitutes a fringing reef dominated by non-branching brain coral species (Faviidae), areas of patchy sand, remnants of dead elkhorn (Acropora palmata) and staghorn (Acropora cervicornis) corals. For this study, sharknose goby (Elacatinus evelynae) cleaning stations were defined as specific localities on the reef used by cleaners for performing their cleaning activities: all cleaning stations were based upon Faviidae coral heads. Corals were not identified to a species level due to the difficulties associated with visual species-level identification (Todd 2008; Forsman et al. 2009). Within a $70 \mathrm{~m}$ by $60 \mathrm{~m}$ section of the reef, known cleaning station coral heads (from 8 years of long-term study; Dunkley et al. 2019b, $n=55$ cleaning stations) were marked, along with an additional 12 control Faviidae 
Fig. $13 \mathrm{D}$ digital workflow to show quantification of a control and sharknose goby (Elacatinus evelynae) cleaning station coral microhabitat traits on Booby Reef, Man O' War Bay, Tobago: (1) In vivo filming, (2), assembled into mesh chunks in PhotoScan Standard (3) 3D model creation in Rhinoceros 3D (see https://youtu.be/ Hyle0D4USdU) and (4) trim to exclude surrounding reef

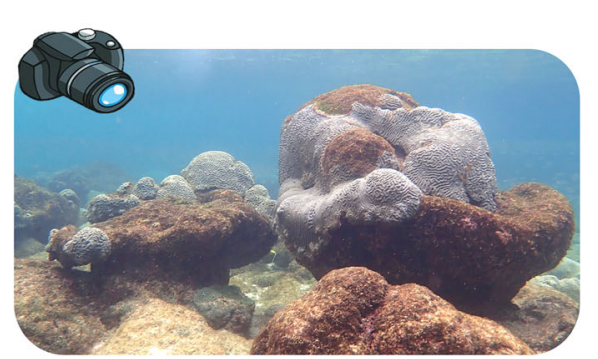

1. Film the coral in vivo
3. Create the 3D digital coral
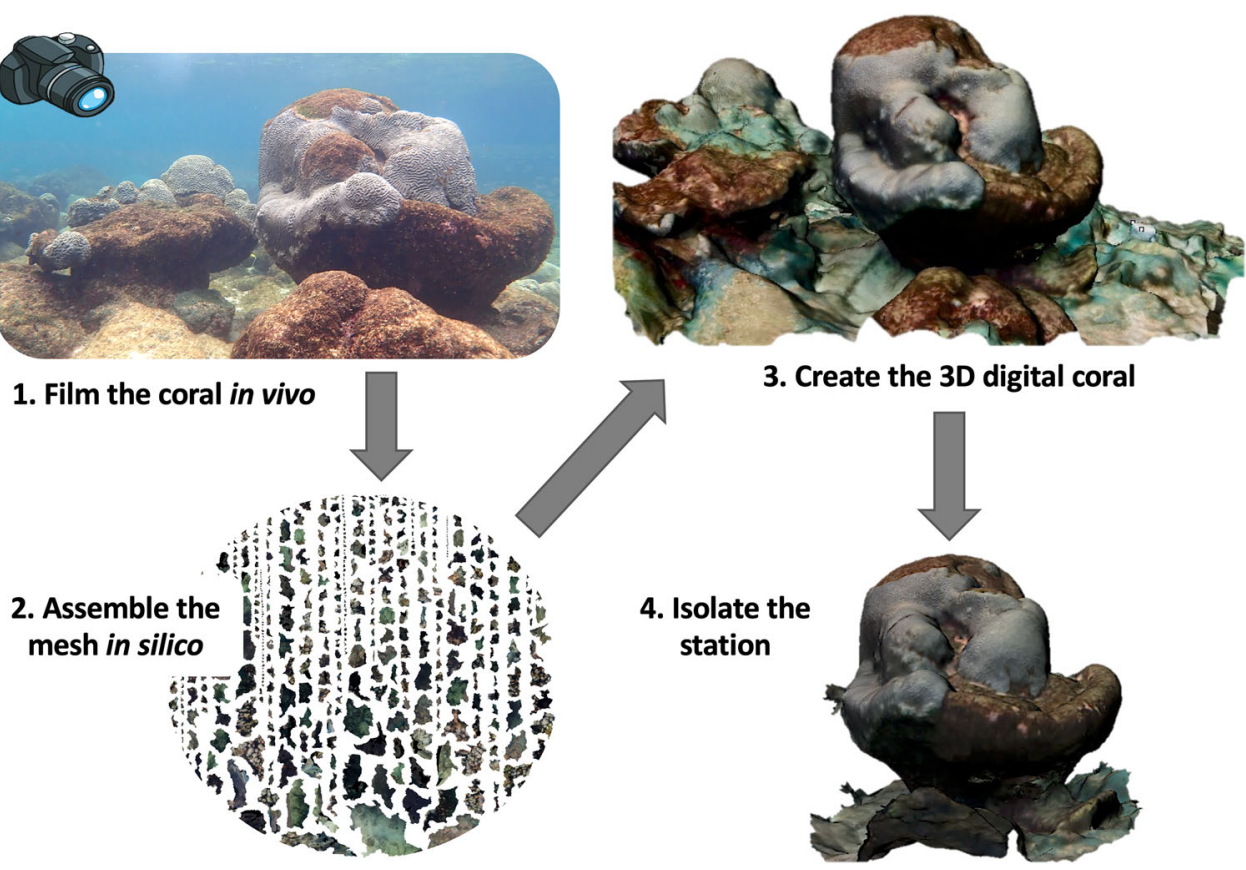

corals. These control corals have never been observed to be occupied by cleaners across 8 years of long-term study at this site (long-term study detailed in Dunkley et al. 2019b).

Cleaner abundance at cleaning stations was quantified using presence/absence surveys $(n=1549$ surveys, mean \pm S.E. surveys per cleaning station $=28.16 \pm 1.34$ ) over a 6-week period in May-July 2016 by daily snorkelling between the hours of 0830 and $1730 \mathrm{~h}$. For each survey, observers $(n=6)$ searched for cleaners at a marked coral head, and in the close vicinity ( $\sim 2 \mathrm{~m}^{3}$ area), for up to 2 min-individual cleaners show strong site fidelity to their cleaning stations (Whiteman and Côté 2002; Harding et al. 2003). A cleaner occupancy value was subsequently assigned to each cleaning station-cleaner occupancy was defined here as the proportion of observations where one or more cleaners were present at the station (range: $0-1$ ).

Between presence/absence surveys, data were also collected on the cleaners' cleaning behaviour using $10 \mathrm{~min}$ focal observations ( $n=223$ observations, mean number observations per cleaning station across 34 cleaning stations \pm S.E. $=6.56 \pm 0.52$, range: $3-13$ observations per station). For each observation, stations were randomly sampled throughout the day and one cleaner was randomly selected from their coral head, and we recorded the duration and frequency of cleaning interactions with clients. Cleaning frequencies, durations and cleaning rate were thus used as a measure of cleaning behaviour. The frequencies and durations represent the total effort in cleaning whilst rates represent this effort per cleaning time (i.e. total cleaning frequency/total cleaning duration). Although clients tolerate closer human approaches when being cleaned
(Giglio et al. 2020), snorkelers maintained a $1 \mathrm{~m}$ distance from the cleaners during observations.

\section{Three-dimensional digital coral data collection}

To create three-dimensional models of the cleaning stations $(n=55)$ and control corals $(n=12)$, video footage was collected with underwater cameras (Olympus GT-4) mounted on monopods, using 1080p resolution and medium sharpness. The physical boundaries of a station were defined as discrete coral head(s) that were not connected to other reef sections (Fig. 1). Filming occurred under ambient light, whilst snorkelling at depths of 1-3 m. At each cleaner station, a cube $\left(6.4 \mathrm{~cm}^{3}\right)$ was placed adjacent to the coral to serve as a scale. The filming process (adapted from Gutierrez-Heredia et al. 2016) was carried out by swimming slowly, in a spiral motion, starting from the top of the coral and moving down towards the base at the seabed whilst changing the camera angle from (1) top-down (parallel to the seabed), (2) at $45^{\circ}$ to the coral and seabed, and (3) planar to the coral. To capture fine-scale spatial features of the coral the filming procedure was repeated for each coral head (station and controls) at two different distances: firstly, with the whole coral in full frame, and then, secondly, moving closer ( $\sim 50 \mathrm{~cm}$ from the coral). This videoing process was repeated three times for each coral to obtain clear, un-obstructed frames in $360^{\circ}$, thus accounting for error in videos from obstruction from floating debris and marine life. The duration of each video correlated with the size of the coral head: larger corals were filmed for longer. This created more images for 
model reconstruction to ensure quality was not lost as a result of increased coral size. Together, our video recording and processing methods created a standardized approach (e.g. across different coral head sizes and light conditions; Raoult et al. 2017). Video footage was converted to still images using QuickTime ${ }^{\mathrm{TM}}$ Player 7.6.6 at an extraction rate of three images per second, resulting in 100-500 images per station with a resolution of $1920 \times 1080$ p. Image sequences were then imported into PhotoScan Standard (Agisoft LLC). Coral models were rendered following the standard workflow sequence in PhotoScan: alignment, dense point cloud generation, mesh building and texture building. Each step was set to medium quality except in the mesh building step where 'meshes maximum face count' was adjusted to 3,000,000 (previously shown to render high resolution models by Young et al. 2017). Final models were compared to still images of corals taken with an Olympus GT-4 camera at four different angles to control for geometric distortion.

\section{Quantifying habitat traits of digital corals}

For each coral head (cleaning stations and control coral), we quantified its height $(\mathrm{cm})$, volume $\left(\mathrm{cm}^{3}\right)$, surface area $\left(\mathrm{cm}^{2}\right)$, linear rugosity (surface roughness/heterogeneity), vector dispersion (another measure of structural complexity; Young et al. 2017), percentage live coral cover and refuge size category. All in silico measurements were recorded using Rhinoceros 3D (Robert McNeel \& Associates). Coral dimensions (height, width and depth) were obtained from three-dimensional models using the 'Line' function: to generate distance measures straight lines were drawn (1) down through the centre of the highest point of the coral, (2) across the diameter of the coral, (3) at the widest point and (4) at the narrowest point (using 'DimAligned' function). These measurements were subsequently used to calculate the volume and surface area for each coral, under the assumption that corals represent an elliptical shape (after Adam 2011). Structural complexity was measured with two metrics: linear rugosity and vector dispersion. Linear rugosity chains $(2 \mathrm{~cm}$ chain link length) were created with a mesh grid with $10 \mathrm{~cm}$ spacing using a custom Python script (https://github.com/grace calvertyoung/ Rhino-Python-3D-Coral-Reefs). Using a consistent spacing allowed a standardisation of the number of chains, as all corals were different sizes. Vector dispersion was calculated at a $1 \mathrm{~cm}$ resolution following Young et al. (2017). Finally, percentage live cover and refuge size was quantified in situ during video collection using the habitat assessment score (defined in Gratwicke and Speight 2005). For each model, habitat that did not constitute the station (sandy seabed, adjacent rocky outcrops etc.) were excluded using a circumference of $10 \mathrm{~cm}$ from the base of the coral (Fig. 1, steps 3 and 4).

\section{Data analysis}

Data were analysed in R version 3.4.3 (R Core Team 2017) using Generalized Linear Models (GLMs), Generalised Linear Mixed Models (GLMM, using 'Ime4'; Bates et al. 2015) and generalized additive models for location, scale and shape (GAMLSS, package "gamlss"; Rigby and Stasinopoulos 2005). Model assumptions and fits were assessed using residual plots (as specified by Bolker et al. 2009) and all continuous predictors were scaled and centred around zero to facilitate model convergence. Best fitting model selection was based on Akaike Information Criterion (AIC) using a backward elimination approach (with delta $<2$ ). The significance of fixed effects was assessed using likelihood ratio tests comparing models with and without the main effect. The presence of potential influential points on model outcomes were checked for (using Cook's D and leverage), and sensitivity analyses were carried out on identified points (Chatterjee and Hadi 2009): the robustness of results was assessed when identified outlier values were temporarily excluded from models. Significant effects that were sensitive to the presence of influential points are stated in the results.

To determine whether cleaning station corals $(n=55)$ versus control corals $(n=12)$ differed in their microhabitat traits; rugosity, vector dispersion, height, percentage live cover and refuge size category were specified as fixed effects in a binomial logistic GLM (with a probit link). Due to collinearity (identified by Variance Inflation Factor values $>3$ ) between height, volume and surface area, surface area to volume ratio was specified as a main effect (replacing volume and surface area, height still included): this removed any issue with collinearity between variables. It was not suitable to remove any one of these variables from all models or carry out a PCA, since we are interested in the effect of each individual trait.

To determine whether microhabitat traits link with cleaner occupancy (range: 0-1) and abundance (range: 0-9 gobies per presence/absence survey), and cleaning behaviours (frequency, duration and rate), only data from cleaning stations $(n=55)$ were used: this removed false zeros from control corals. Due to further issues with collinearity between height and surface area to volume ratio, we first carried out a sequential regression using these two variables. This method involves regressing the less important variable (in this case specified as surface area to volume ratio) against the other (height) and replacing the less important variable with the residuals from the regression-this disentangles unique from shared contributions from the two variables (Graham 2003). Following 


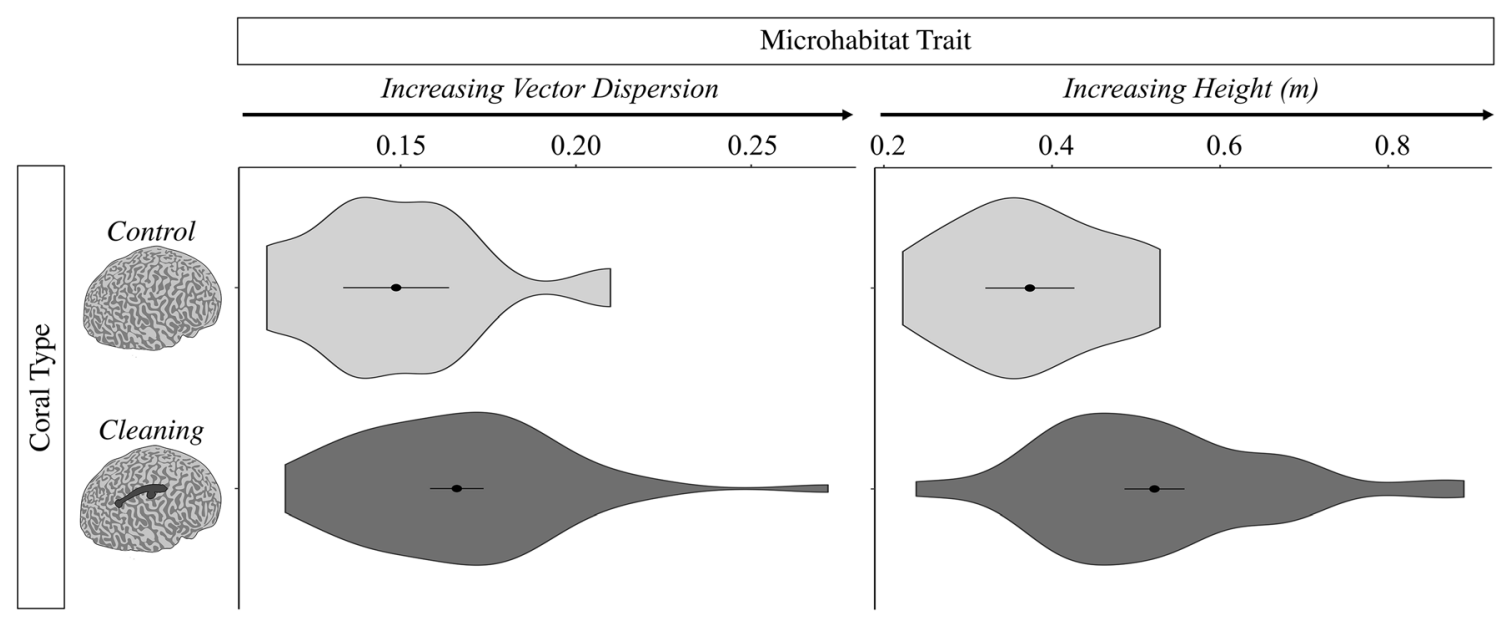

Fig. 2 Microhabitat traits of sharknose goby (Elacatinus evelynae) cleaning stations. The outer shapes of the violin plot represent the range of vector dispersions (complexity measure - uniformity in angles of a surface; Young et al. 2017) and heights (m) across

sequential analysis there was no significant correlation between the variable 'height' and the sequential model residuals. This residual variable was independently calculated for and specified as, a main effect in all further models.

To test for a link between microhabitat traits and occupancy (one value per station); rugosity, vector dispersion, height, surface area to volume ratio residuals, percentage live cover and refuge size category were specified as fixed effects in a Gaussian GLM (with identity link). Prior to analysis, occupancy values were logit transformed since other methods for analysing proportion data (e.g. binomial and beta models) produced poor fitting and overdispersed models (assessed using residual plots). To test for a link between microhabitat traits and cleaner abundance, the same microhabitat traits (including surface area to volume residuals) were specified as fixed effects in a negative binomial GLM. The negative binomial family replaced an overdispersed Poisson model. For this GLM, multiple cleaner abundance counts were aggregated to total amounts per station (following Kratschmer et al. 2018), and an offset was specified, with a $\log$ transformation, which accounted for the number of presence/absence surveys per station.

To determine whether microhabitat traits link with cleaning behaviour (frequency, duration and rate) one GAMLSS (for frequency, replacing an overdispersed GLMM) and two GLMMs were specified all with the following fixed effects: rugosity, vector dispersion, height, surface area to volume ratio residuals, percentage live cover and refuge size. Since more than one observer collected behavioural data $(n=6)$, "Observer ID" was included as a random effect in all three models. Data were used on stations $(n=34)$ for which multiple observations cleaning and control corals, while shape thickness shows how frequently these data values occurred. Point and lines show mean \pm $95 \% \mathrm{CI}$

( $\min n=3$ ) were carried out. For cleaning frequencies, all observation data were included ( $n=223$, contained zeros) whilst for rate and duration, only data containing observations where cleaning events occurred, were included in analyses ( $n=132$ observation, contained no zeros). Cleaning frequency (modelled using beta-binomial GAMLSS, replacing an overdispersed binomial GLMM) and rate (modelled using an inverse Gaussian family with an inverse link) represent the summed interaction frequency/duration for each cleaning interaction within each observation (single value per observation), whilst cleaning duration data (modelled using Gamma family and log link) represented each single individual cleaning event and its respective interaction length (multiple values per observation). Thus, for duration, ObservationID (a unique value assigned to each observation) was also specified as a random effect. The total time for each focal observation accounted for the amount of time a cleaner was out of view and thus varied across observations: for cleaning frequency, values were therefore weighted by observation length. This correction was not necessary for cleaning rate and duration models since their values were independent from observation length. Prior to analysis, cleaning rate values (range: $0.03-1.00$ ) were rescaled from one to ten using the "scales" package (Wickham 2017): this method does not remove the variability between values, but simply transforms data to aid model fit. Finally, to determine whether significant relationships between microhabitat traits and cleaning behaviours were mediated and/or moderated by occupancy/abundance values, station occupancy and cleaner abundance (number of cleaners on the station for each observation) were added to all three final models as individual and interaction terms (occupancy/ abundance separately interacted with trait terms). Across 
some studies of Caribbean cleaning interactions, cleaning patterns have been shown to vary with time of day (Cote and Molloy 2003; Sikkel et al. 2004, 2005). However, across 8 years of long-term data collected from the same study reef (including data used in this study), Dunkley et al. (2020) consistently found no effect of time of day on cleaning frequencies and durations (as also shown by Grutter et al. 2002; Whiteman \& Cote 2002). To avoid overfitting our already complex models, we did not include time of day in our behavioural analyses.

\section{Results}

\section{Do cleaning stations show specific microhabitat traits?}

Cleaning stations $(n=55)$ were significantly taller than control corals $(n=12)$ and had more structurally complex surfaces (Fig. 2, GLM, model $R^{2}=39.0 \%$, height: $\beta=1.00$, $\chi_{1}^{2}=11.00, p<0.001$, vector dispersion (uniformity in angles of a surface; Young et al. 2017): $\beta=0.54$, $\chi^{2}{ }_{1}=4.13, p=0.042$ ). Cleaning stations also had lower surface area to volume ratios compared to control corals (GLM, $\beta=-0.62, \chi^{2}{ }_{1}=6.27, p=0.012$ ) although this result became non-significant when an influential point (relating to a control coral) was temporarily removed $(p>0.20)$. There were no other significant differences between stations and control coral habitat traits (GLM, $p>0.05)$.

\section{Do microhabitat traits link with cleaner occupancy patterns?}

Generally, cleaning station microhabitat traits did not predict how frequently cleaning stations were occupied (mean \pm S.E. occupancy across stations $=0.56 \pm 0.04$, GLM, all predictors $p>0.05$ ). However, cleaner occupancy tended to increase with the complexity of the coral surface $\left(\mathrm{GLM}_{\text {model }} R^{2}=6.1 \%\right.$, vector dispersion: $\beta=0.44$, $F_{1,53}=3.42, p=0.070, p=0.033$ when one influential point (station) removed: influential station vector dispersion value $=0.27$, mean \pm S.E. dispersion value across stations $=0.17 \pm 0.004, \quad$ influential station occupancy $=0.55$ ). Microhabitat traits did not significantly predict the variable abundance of cleaners on stations (GLM, all traits $p>0.05$, up to nine cleaners occupied an individual station across time, mean cleaner abundance across presence/absence surveys \pm S.E. $=0.97 \pm 0.03$ ).

\section{Do microhabitat traits link with cleaning behaviour?}

Out of 223 observations across 34 cleaning stations, cleaning was observed 308 times across 132 observations. Cleaning occurred less frequently, and bouts were longer, at taller cleaning stations (Fig. 3, cleaning frequency: GAMLSS, ${ }_{\text {model }} R^{2}=5.8 \%, \chi^{2}{ }_{1}=5.46, p=0.019$, cleaning duration: GLMM, $\operatorname{model}^{2}=22.9 \%, \quad \chi_{1}^{2}=4.58$, $p=0.032$ ). Cleaning durations also increased with refuge size category (GLMM, $\chi^{2}{ }_{1}=4.10, p=0.043, p=0.053$ when one influential cleaning event removed). Cleaning rates, which averaged 0.26 cleaning events per second $( \pm 0.02$, S.E. $)$, were lower at taller cleaning stations but increased with structural complexity (Fig. 3, GLMM, ${ }_{\text {model }} R^{2}=24.4 \%$, height $=\chi_{1}^{2}=5.97, p=0.015$, vector dispersion $=6.71, p=0.010$ ). Links between cleaning behaviours and microhabitat traits were not mediated/moderated by cleaner presence: generally, cleaning behaviours were not predicted by cleaning station occupancy or the abundance of cleaners, although cleaning frequencies tended to negatively link with occupancy (GAMLSS, $\beta=-0.17, \chi^{2}{ }_{1}=3.45, p=0.063$, height still remained significant when occupancy and cleaner abundance main effects included in model).

\section{Discussion}

Here, for the first time, we demonstrate that the cleaning stations of a predominant Caribbean cleaner, the sharknose goby (Elacatinus evelynae), can be distinguished from nonstation corals by increased height and structural complexity (vector dispersion). Although microhabitat trait variation predicted the occurrence of cleaning stations, they did not predict cleaner occupancy nor abundance patterns of occupied cleaning stations. Variations in coral morphology, however, in terms of height, vector dispersion and refuge size did promote variations in cleaning frequencies, durations and rates. Cleaning events were longer but occurred at a lower frequency and rate at taller corals. Events were also longer when refuge sizes were larger, whilst rates increased with structural complexity (vector dispersion). Together, this study highlights the importance of variation in coral morphology for local cleaner distribution and thus its potential role in moderating the dynamics of cleaning interactions on a larger scale.

Cleaning gobies show strong site fidelity to their cleaning stations (Whiteman and Côté 2002; Harding et al. 2003), are assumed to have short lifespans (mean age documented $<50$ days in White et al. 2007) and remain in direct contact with their coral (apart from when cleaning, and the occasional competition-induced move to adjacent coral; Whiteman and Côté 2002; Côté and Soares 2011). 
Fig. 3 Sharknose goby (Elacatinus evelynae) cleaning station microhabitat traits which predicted their cleaning frequencies, durations and rates. Lines are based on model coefficients (GAMLSS or GLMM) while points represent raw or mean averaged data. Cleaning event values were rescaled from one to 10 to aid model fit. Log transformations were performed for figure clarity. Height, refuge size and vector dispersion are illustrated on a three-

dimensional model of one cleaning station from Booby Reef, Man O’ War Bay, Tobago
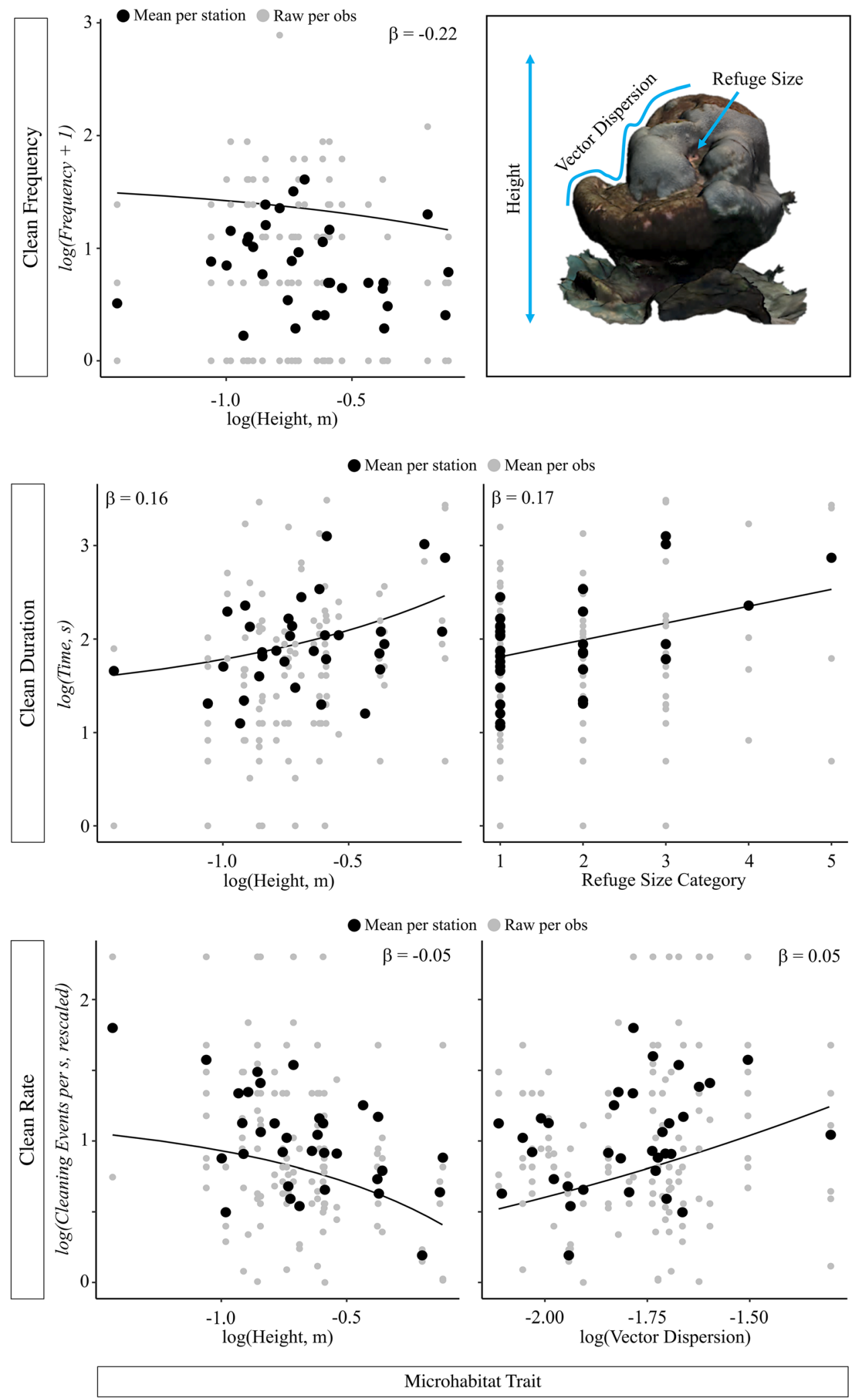

Cleaners adult distribution patterns may thus be, in-part, governed by their larval post-settlement success/settlement site. Elacatinus gobies form monogamous pairs (Harding et al. 2003), regularly spawn (E. evelynae spawning interval: 9-20 days) and produce high clutch sizes ( $E$. evelynae: 200-250 eggs clutch $^{-1}, 10-50 \%$ survival to 
settlement). Importantly, these larvae have lengthy pelagic larval periods (E. evelynae: settle 30-40 days post hatching; Colin 1975; Olivotto et al. 2005; Majoris et al. 2018b) and for a closely related species (E. lori), larvae have been documented to travel $\sim 2 \mathrm{~km}$ from their parent site (D'Aloia et al. 2015). Taller corals which stand above others, may thus 'catch' pre-settlement larvae, whilst increased surface complexity can reduce larvae/adult predation risk (Beukers and Jones 1998; Almany 2004) and alter larval density-dependent mortality once settled (Johnson 2007), together promoting the formation of cleaning stations. However, if our results were simply down to random larvae settlement patterns mediated by their post-settlement survival success, we would also expect coral heads with larger surface areas to also function as cleaning stations (similar to Losey 1974), which was not the case (non-station corals were consistently observed to be unoccupied across 8 years of long-term study; Dunkley et al. 2019b). In addition, although gobies do generally stay affiliated with their coral heads, some localised movements by adults are observed between neighbouring heads (up to $\sim 5 \mathrm{~m}$ distance; Dunkley et al. 2019a). Thus, by flexibly moving between corals, adult cleaners may more efficiently increase their fitness by benefitting from differential resources from different coral heads. Choice experiments would help decipher the absolute habitat preferences for this species.

Settlement of coral reef fish in their habitat is complicated, and it is very unlikely that finer scale settlement patterns within an environment are a matter of chance (Victor 1986). Many coral reef fish larvae rely on a combination of cues to control their settlement site selection, including visual, olfactory and acoustic stimuli (Montgomery et al. 2001; Lecchini et al. 2005). It is not clear, however, how sensitive such cues are to finer scale variations (i.e. between corals of the same family as investigated here). Some fish also base settlement cues on the presence of conspecifics and not on the corals characteristics, since the presence of conspecifics could be an indicator of habitat quality (Öhman et al. 1998; Lecchini et al. 2005). This hypothesis is supported for E. prochilos (see Whiteman and Côté 2004). However, since density dependence can influence settlement mortality (Johnson 2007), in the current study, we would perhaps expect occupancy/abundance patterns to correlate with microhabitat traits, which we did not observe (in parallel with Wilson and Osenberg 2002, assuming corals are at full carrying capacity, with coral heads assumed to be saturated at very low densities; Whiteman and Côté 2004).

Taller corals also played an important role in influencing the dynamics of cleaning interactions. Investments in cleaning interactions are governed by risk: clients give up foraging time (Grutter et al. 2002) and may be more vulnerable to predators (although both cleaners and clients are thought to be afforded protection to some extent; Cheney et al. 2008; Soares et al. 2012). Cleaning at a taller coral may provide both cleaners and clients with a visual advantage by creating a greater field of view, lowering predation risk (by providing a better view of approaching predators; Nemeth 1998) and facilitating longer cleaning events. Indeed, for a common client of cleaning gobies, Stegastes partitus (see Dunkley et al. 2019b), a limited field of view around their territorial site altered their risktaking behaviour (Rilov et al. 2007). Further exploration of this hypothesis however, will rely on knowledge concerning the visual acuity of cleaner fish and their clients, which is currently unknown (although it is likely to correlate with eye size; Caves et al. 2017). The assumption that station habitat traits that reduce risk and are beneficial for cleaning patterns, can also be supported by our result that longer cleaning bouts were observed at stations with increase refuge size, and that cleaning rates were higher with increased complexity (creating crevices and cracks). Similar to cleaner wrasse (species unknown; Ferrari et al. 2018), here cleaning gobies were found to associate with cleaning stations that showed an increased variation in slopes. The availability of refuges and fine-scale variations in structural complexity $(1 \mathrm{~cm}$ vector dispersion) may provide a 'safety net' for small bodied cleaners (max $4.5 \mathrm{~cm}$ fork length; Cheney and Côté 2003) minimising their risk to threats by reducing access/mobility options for larger predators. Indeed, Ferrari et al. 2018) hypothesized that a strong association with sponges by the spongedwelling facultative-cleaning ecotype of sharknose gobies could be explained by the shelter these benthic organisms may provide. It should be highlighted however that if taller corals are more preferable resources (compared to other coral geometries), only gobies expressing beneficial and competitive phenotypes may be expected to dominate such environments, with variation in phenotypes also leading to variations in cleaning behaviour (Dunkley et al. 2019a). Correlating the occurrence of different cleaner behavioural phenotypes (e.g. personality traits) with station microhabitat traits, and their spatial locations may thus be beneficial for future study.

Cleaning patterns can also be goverened by the feedback behaviours of their clients (Dunkley et al. 2019a), and clients may use the "landmark feature" of cleaning stations to locate cleaners (Kulbicki and Arnal 1999; Losey 1974) with taller or larger features being easier for clients to locate (Braithwaite and De Perera 2006). In turn, clients may then learn to associate these specific features (e.g. "large spherical corals") with the cleaners (Losey 1974). Indeed, in sparser, heterogeneous environments, organisms tend to aggregate around habitat structures (García-Charton and Pérez-Ruzafa 2001) and thus taller stations may 
promote enhanced client numbers/diversity visiting the location-creating foraging choice options for the cleaner. Higher energy gains can be obtained through consuming higher quality foods, feeding for longer and increasing diet breadth (Toscano et al. 2016). Since different clients host species specific parasite assemblages (Grutter 1994), cleaners could maximise their energy loss versus gains by selectively cleaning different client types to optimize their nutrition/energy through fewer interactions. Some client types will be restricted in their spatial distribution on reef by the microhabitat features (Tolimieri 1995) and their reef-use behaviour (e.g. territorial species) however. Taller stations may thus also allow a greater range of 'favourable client types', hosting higher parasite burdens/diversity (e.g. predators, larger body sizes; Poulin and Rohde 1997) to access the cleaner. Incorporation of client functional traits, abundance, diversity, and behaviour data should now thus be considered in future study.

The high structural complexity of coral reefs, which is a defining and vital component of a healthy environment, is under threat from a suite of natural and anthropogenic disturbances (Magel et al. 2019). Here we show that the prevalence and dynamics of cleaning interactions on a local scale, which are also thought to be a vital component of a healthy reef (Clague et al. 2011; Waldie et al. 2011; Demairé et al. 2020), may be vulnerable to even fine-scale changes in microhabitat structure, especially with regards to coral height. Through their large number of interactions with a diversity of client species, cleaning interactions can also drive patterns of fish diversity themselves (Bronstein 2015), playing an important role in the ecological community structure (Floeter et al. 2007; Quimbayo et al. 2018) - changes in the dynamics of cleaning interactions could thus hold strong consequences for the associated reef fish community. It is important to note however, that like all mutualisms, cleaning interactions are highly context dependent: interaction outcomes vary temporally (Cote and Molloy 2003; Sikkel et al. 2004, 2005; Dunkley et al. 2019a, b, 2020) and spatially (Côté 2000; Sikkel et al. 2000; Dunkley et al. 2020; Romain et al. 2020). Whilst we show that microhabitat traits play a role in governing local interaction patterns, a host of additional interlinked contextual factors can influence interaction outcomes (e.g. client identity and abundance; Dunkley et al 2020). It is therefore difficult to determine at this stage, what our findings mean under wide-scale ecosystem degradation scenarios. Compared to the Indo-Pacific, Caribbean reef communities naturally exhibit lower species diversity meaning they are already less resilient to decline and degradation (Bellwood et al. 2004). It is therefore vital that we gain further knowledge of the finer scale habitat requirements of such keystone species in the Caribbean to determine how habitat losses/changes to the reef geometry may both directly and indirectly impact reef communities.

Acknowledgements This work was funded by a Knowledge Economy Skills Scholarship (KESS 2, awarded to K.E.W), supported by European Social Funds (ESF) through the Welsh Government. Knowledge Economy Skills Scholarships (KESS) is a pan-Wales higher level skills initiative led by Bangor University on behalf of the HE sector in Wales. It is part funded by the Welsh Government's European Social Fund (ESF) convergence programme for West Wales and the Valleys. This research was also funded by a Natural Environment Research Council GW4+ studentship to K.D. (NE/L002434/ 1). We thank Patricia Turpin (President of Environment Tobago) for field facilities, Drs Amy Ellison, Ryan Mohammed and Environment Research Institute Charlotteville (ERIC) for field support and undergraduate students Stephen Cheung, Molly Fairclough and Therese McAlister for help with in silico data collection of 3D modelling habitat metrics.

Author contributions KEW, KD, SEP, and JC designed the project and collected the data; GCY provided advice on 3-D modelling; KEW with KD conducted the statistical analyses and drafted the manuscript; all authors contributed to manuscript revisions.

Data availability Data are available upon request.

\section{Declarations}

Conflict of interest On behalf of all authors, the corresponding author states that there is no conflict of interest.

Open Access This article is licensed under a Creative Commons Attribution 4.0 International License, which permits use, sharing, adaptation, distribution and reproduction in any medium or format, as long as you give appropriate credit to the original author(s) and the source, provide a link to the Creative Commons licence, and indicate if changes were made. The images or other third party material in this article are included in the article's Creative Commons licence, unless indicated otherwise in a credit line to the material. If material is not included in the article's Creative Commons licence and your intended use is not permitted by statutory regulation or exceeds the permitted use, you will need to obtain permission directly from the copyright holder. To view a copy of this licence, visit http://creativecommons. org/licenses/by/4.0/.

\section{References}

Adam TC (2011) High-quality habitat and facilitation ameliorate competitive effects of prior residents on new settlers. Oecologia 166:121-130

Almany GR (2004) Differential effects of habitat complexity, predators and competitors on abundance of juvenile and adult coral reef fishes. Oecologia 141:105-113

Bates D, Maechler M, Bolker B, Walker S (2015) Fitting linear mixed-effects models using lme4. Journal of Statistical Software 67:1-48

Bellwood DR, Hughes TP, Folke C, Nystrom M (2004) Confronting the coral reef crisis. Nature 429:827-833

Beukers JS, Jones GP (1998) Habitat complexity modifies the impact of piscivores on a coral reef fish population. Oecologia 114:50-59

Bolker BM, Brooks ME, Clark CJ, Geange SW, Poulsen JR, Stevens MH, White JS (2009) Generalized linear mixed models: a 
practical guide for ecology and evolution. Trends in Ecology \& Evolution 24:127-135

Booth DJ, Wellington G (1998) Settlement preferences in coral-reef fishes: Effects on patterns of adult and juvenile distributions, individual fitness and population structure. Australian Journal of Ecology 23:274-279

Boström-Einarsson L, Bonin MC, Munday PL, Jones GP (2018) Loss of live coral compromises predator-avoidance behaviour in coral reef damselfish. Scientific Reports 8:1-9

Braithwaite V, De Perera TB (2006) Short-range orientation in fish: how fish map space. Marine and Freshwater Behaviour and Physiology 39:37-47

Bronstein JL (2015) Mutualism. Oxford University Press, Oxford, UK

Caves EM, Sutton TT, Johnsen S (2017) Visual acuity in ray-finned fishes correlates with eye size and habitat. Journal of Experimental Biology 220:1586-1596

Chatterjee S, Hadi AS (2009) Sensitivity analysis in linear regression. John Wiley \& Sons

Cheney KL, Côté IM (2001) Are Caribbean cleaning symbioses mutualistic? Costs and benefits of visiting cleaning stations to longfin damselfish. Animal Behaviour 62:927-933

Cheney KL, Côté IM (2003) Do ectoparasites determine cleaner fish abundance? Evidence on two spatial scales. Marine Ecology Progress Series 263:189-196

Cheney KL, Bshary R, Grutter AS (2008) Cleaner fish cause predators to reduce aggression toward bystanders at cleaning stations. Behavioral Ecology 19:1063-1067

Clague GE, Cheney KL, Goldizen AW, McCormick MI, Waldie PA, Grutter AS (2011) Long-term cleaner fish presence affects growth of a coral reef fish. Biology Letters 7:863-865

Colin PL (1975) The neon gobies: the comparative biology of the gobies of the genus Gobiosoma, subgenus Elacatinus,(Pisces: Gobiidae) in the tropical western North Atlantic Ocean. TFH Publications

Côté IM (2000) Evolution and ecology of cleaning symbiosis in the sea. In Gibson RN, Barnes M (eds) Oceanography and marine biology: an annual review. Taylor \& Francis pp 311-355

Côté IM, Molloy PP (2003) Temporal variation in cleanerfish and client behaviour: Does it reflect ectoparasite availability? Ethology 109:487-499

Côté IM, Soares MC (2011) Gobies as cleaners The Biology of Gobies. Science Publishers, St. Helie, pp525-551

Crowder LB, Cooper WE (1982) Habitat structural complexity and the interaction between bluegills and their prey. Ecology 63:1802-1813

D'Aloia CC, Bogdanowicz SM, Francis RK, Majoris JE, Harrison RG, Buston PM (2015) Patterns, causes, and consequences of marine larval dispersal. Proceedings of the National Academy of Sciences 112:13940-13945

Demairé C, Triki Z, Binning SA, Glauser G, Roche DG, Bshary R (2020) Reduced access to cleaner fish negatively impacts the physiological state of two resident reef fishes. Marine Biology 167:1-10

Dunkley K, Cable J, Perkins SE (2020) Consistency in mutualism relies on local, rather than wider community biodiversity. Sci Rep. https://www.nature.com/articles/s41598-020-78318-x

Dunkley K, Cable J, Perkins SE (2018) The selective cleaning behaviour of juvenile blue-headed wrasse (Thalassoma bifasciatum) in the Caribbean. Behavioural Processes 147:5-12

Dunkley K, Ioannou CC, Whittey KE, Cable J, Perkins SE (2019a) Cleaner personality and client identity have joint consequences on cleaning interaction dynamics. Behavioral Ecology

Dunkley K, Ellison AR, Mohammed RS, van Oosterhout C, Whittey KE, Perkins SE, Cable J (2019b) Long-term cleaning patterns of the sharknose goby (Elacatinus evelynae). Coral Reefs:1-10
Feder HM (1966) Cleaning symbiosis in the marine environment. Symbiosis 1:327-380

Ferreira CE, Goncçalves JE, Coutinho R (2001) Community structure of fishes and habitat complexity on a tropical rocky shore. Environmental Biology of Fishes 61:353-369

Ferrari R, Figueira WF, Pratchett MS, Boube T, Adam A, Kobelkowsky-Vidrio T, Doo SS, Atwood TB, Byrne M (2017) 3D photogrammetry quantifies growth and external erosion of individual coral colonies and skeletons. Scientific Reports 7:1-9

Ferrari R, Malcolm HA, Byrne M, Friedman A, Williams SB, Schultz A, Jordan AR, Figueira WF (2018) Habitat structural complexity metrics improve predictions of fish abundance and distribution. Ecography 41:1077-1091

Floeter SR, Vazquez DP, Grutter AS (2007) The macroecology of marine cleaning mutualisms. Journal of Animal Ecology 76:105-111

Forsman ZH, Barshis DJ, Hunter CL, Toonen RJ (2009) Shapeshifting corals: molecular markers show morphology is evolutionarily plastic in Porites. BMC evolutionary biology 9:45

García-Charton J, Pérez-Ruzafa A (2001) Spatial pattern and the habitat structure of a Mediterranean rocky reef fish local assemblage. Marine Biology 138:917-934

Giglio VJ, Nunes JACC, Ferreira CEL, Blumstein DT (2020) Client reef fish tolerate closer human approaches while being cleaned. J Zool 1-6

González-Rivero M, Harborne AR, Herrera-Reveles A, Bozec Y-M, Rogers A, Friedman A, Ganase A, Hoegh-Guldberg O (2017) Linking fishes to multiple metrics of coral reef structural complexity using three-dimensional technology. Scientific Reports $7: 1-15$

Grabowski JH (2004) Habitat complexity disrupts predator-prey interactions but not the trophic cascade on oyster reefs. Ecology 85:995-1004

Graham MH (2003) Confronting multicollinearity in ecological multiple regression. Ecology 84:2809-2815

Graham N, Nash K (2013) The importance of structural complexity in coral reef ecosystems. Coral Reefs 32:315-326

Gratwicke B, Speight MR (2005) The relationship between fish species richness, abundance and habitat complexity in a range of shallow tropical marine habitats. Journal of Fish Biology 66:650-667

Grutter AS (1994) Spatial and temporal variations of the ectoparasites of seven reef fish species from Lizard Island and Heron Island, Australia. Marine Ecology Progress Series 115:21-30

Grutter AS, McCallum H, Lester RJG (2002) Optimising cleaning behaviour: minimising the costs and maximising ectoparasite removal. Marine Ecology Progress Series 234:257-264

Gutierrez-Heredia L, Benzoni F, Murphy E, Reynaud EG (2016) End to end digitisation and analysis of three-dimensional coral models, from communities to corallites. PLoS One 11

Harding JA, Almany GR, Houck LD, Hixon MA (2003) Experimental analysis of monogamy in the Caribbean cleaner goby, Gobiosoma evelynae. Animal Behaviour 65:865-874

Huebner LK, Chadwick NE (2012) Reef fishes use sea anemones as visual cues for cleaning interactions with shrimp. Journal of Experimental Marine Biology and Ecology 416:237-242

Hunt CL, Kelly GR, Windmill H, Curtis-Quick J, Conlon H, Bodmer MD, Rogers AD, Exton DA (2019) Aggregating behaviour in invasive Caribbean lionfish is driven by habitat complexity. Scientific Reports 9:1-9

Johnson DW (2007) Habitat complexity modifies post-settlement mortality and recruitment dynamics of a marine fish. Ecology 88:1716-1725

Johnson WS, Ruben P (1988) Cleaning behavior of Bodianus rufus, Thalassoma bifasciatum, Gobiosoma evelynae, and Periclimenes 
pedersoni along a depth gradient at Salt River SubmarineCanyon, St-Croix. Environmental Biology of Fishes 23:225-232

Jones CG, Lawton JH, Shachak M (1994) Organisms as ecosystem engineers Ecosystem Management. Springer, pp130-147

Kratschmer S, Kriechbaum M, Pachinger B (2018) Buzzing on top: Linking wild bee diversity, abundance and traits with green roof qualities. Urban ecosystems 21:429-446

Kulbicki M, Arnal C (1999) Cleaning of fish ectoparasites by a palaemonidae shrimp on soft bottoms in New Caledonia. Cybium 23:101-104

Lange I, Perry C (2020) A quick, easy and non-invasive method to quantify coral growth rates using photogrammetry and 3D model comparisons

Lecchini D, Planes S, Galzin R (2005) Experimental assessment of sensory modalities of coral-reef fish larvae in the recognition of their settlement habitat. Behavioral Ecology and Sociobiology 58:18-26

Limbaugh C (1961) Cleaning symbiosis. Scientific American 205:42-49

Losey GS (1974) Cleaning symbiosis in Puerto Rico with comparison to the tropical Pacific. Copeia, American Society of Ichthyologists and Herpetologists 4:960-970

Magel JM, Burns JH, Gates RD, Baum JK (2019) Effects of bleaching-associated mass coral mortality on reef structural complexity across a gradient of local disturbance. Scientific Reports 9:1-12

Majoris JE, D'Aloia CC, Francis RK, Buston PM (2018) Differential persistence favors habitat preferences that determine the distribution of a reef fish. Behavioral Ecology 29:429-439

Majoris JE, Francisco FA, Atema J, Buston PM (2018b) Reproduction, early development, and larval rearing strategies for two sponge-dwelling neon gobies, Elacatinus lori and E. colini. Aquaculture 483:286-295

Montgomery JC, Tolimieri N, Haine OS (2001) Active habitat selection by pre-settlement reef fishes. Fish and Fisheries 2:261-277

Munday PL (2004) Habitat loss, resource specialization, and extinction on coral reefs. Global Change Biology 10:1642-1647

Nemeth RS (1998) The effect of natural variation in substrate architecture on the survival of juvenile bicolor damselfish. Environmental Biology of Fishes 53:129-141

Oates J, Manica A, Bshary R (2010) Roving and service quality in the cleaner wrasse Labroides bicolor. Ethology 116:309-315

Öhman MC, Munday PL, Jones GP, Caley MJ (1998) Settlement strategies and distribution patterns of coral-reef fishes. Journal of Experimental Marine Biology and Ecology 225:219-238

Olivotto I, Zenobi A, Rollo A, Migliarini B, Avella M, Carnevali O (2005) Breeding, rearing and feeding studies in the cleaner goby Gobiosoma evelynae. Aquaculture 250:175-182

Petren K, Case TJ (1998) Habitat structure determines competition intensity and invasion success in gecko lizards. Proceedings of the National Academy of Sciences 95:11739-11744

Poulin R, Rohde K (1997) Comparing the richness of metazoan ectoparasite communities of marine fishes: controlling for host phylogeny. Oecologia 110:278-283

Price DM, Robert K, Callaway A, Hall RA, Huvenne VA (2019) Using 3D photogrammetry from ROV video to quantify coldwater coral reef structural complexity and investigate its influence on biodiversity and community assemblage. Coral Reefs 38:1007-1021

Quimbayo JP, Cantor M, Dias MS, Grutter AS, Gingins S, Becker JHA, Floeter SR (2018) The global structure of marine cleaning mutualistic networks. Global Ecology and Biogeography 27:1238-1250

Raoult V, Reid-Anderson S, Ferri A, Williamson J (2017) How Reliable Is Structure from Motion (SfM) over Time and between
Observers? A Case Study Using Coral Reef Bommies. Remote Sens 9:740

R Core Team (2017) R: A language and environment for statistical computing. R Foundation for Statistical Computing, Vienna, Austria URL https://www.R-project.org/. (Last accessed: 23/10/ 18)

Reaka-Kudla ML (1997) The global biodiversity of coral reefs: a comparison with rain forests. Biodiversity II: Understanding and Protecting Our Biological Resources 2:551

Reichert J, Schellenberg J, Schubert P, Wilke T (2016) 3D scanning as a highly precise, reproducible, and minimally invasive method for surface area and volume measurements of scleractinian corals. Limnology and Oceanography: Methods 14:518-526

Rigby RA, Stasinopoulos DM (2005) Generalized additive models for location, scale and shape. Journal of the Royal Statistical Society Series C-Applied Statistics 54:507-544

Rilov G, Figueira W, Lyman S, Crowder L (2007) Complex habitats may not always benefit prey: linking visual field with reef fish behavior and distribution. Marine Ecology Progress Series 329:225-238

Romain JJ, Exton DA, Smith DJ, Rose A, Vondriska C, Titus BM (2020) Comparative cleaning behaviour of Pederson's cleaner shrimp (Ancylomenes pedersoni) between geographically close yet ecologically dissimilar coral reef habitats. J Mar Biol Assoc UK 100(7):1093-1106

Sazima I, Moura R, Rodrigues M (1999) A juvenile sharksucker, Echeneis naucrates (Echeneidae), acting as a station-based cleaner fish. Cybium 23:377-380

Sikkel PC, Fuller CA, Hunte W (2000) Habitat/sex differences in time at cleaning stations and ectoparasite loads in a Caribbean reef fish. Mar Ecol Prog Ser 193:191-199

Sikkel PC, Cheney KL, Côté IM (2004) In situ evidence for ectoparasites as a proximate cause of cleaning interactions in reef fish. Anim Behav 68:241-247

Sikkel PC, Herzlieb SE, Kramer DL (2005) Compensatory cleanerseeking behavior following spawning in female yellowtail damselfish. Mar Ecol Prog Ser 296:1-11

Soares MC, Bshary R, Cardoso SC, Cote IM, Oliveira RF (2012) Face Your Fears: Cleaning Gobies Inspect Predators despite Being Stressed by Them. PLoS ONE 7:e39781

Storlazzi CD, Dartnell P, Hatcher GA, Gibbs AE (2016) End of the chain? Rugosity and fine-scale bathymetry from existing underwater digital imagery using structure-from-motion (SfM) technology. Coral Reefs 35:889-894

Streit RP, Bellwood DR (2018) Strong homing does not predict high site fidelity in juvenile reef fishes. Coral Reefs 37:99-103

Todd PA (2008) Morphological plasticity in scleractinian corals. Biological Reviews 83:315-337

Tolimieri N (1995) Effects of microhabitat characteristics on the settlement and recruitment of a coral reef fish at two spatial scales. Oecologia 102:52-63

Toscano BJ, Gownaris NJ, Heerhartz SM, Monaco CJ (2016) Personality, foraging behavior and specialization: integrating behavioral and food web ecology at the individual level. Oecologia 182:55-69

Vaughan DB, Grutter AS, Costello MJ, Hutson KS (2017) Cleaner fishes and shrimp diversity and a re-evaluation of cleaning symbioses. Fish and Fisheries 18:698-716

Vergés A, Vanderklift MA, Doropoulos C, Hyndes GA (2011) Spatial patterns in herbivory on a coral reef are influenced by structural complexity but not by algal traits. PLoS One 6

Victor BC (1986) Larval settlement and juvenile mortality in a recruitment-limited coral reef fish population. Ecological Monographs 56:145-160 
Waldie PA, Blomberg SP, Cheney KL, Goldizen AW, Grutter AS (2011) Long-term effects of the cleaner fish Labroides dimidiatus on coral reef fish communities. PLoS ONE 6:e21201

White JW, Grigsby CJ, Warner RR (2007) Cleaning behavior is riskier and less profitable than an alternative strategy for a facultative cleaner fish. Coral Reefs 26:87-94

Whiteman EA, Côté IM (2002) Cleaning activity of two Caribbean cleaning gobies: intra- and interspecific comparisons. Journal of Fish Biology 60:1443-1458

Whiteman EA, Côté IM (2004) Individual differences in microhabitat use in a Caribbean cleaning goby: a buffer effect in a marine species? Journal of Animal Ecology 73:831-840

Wickham H (2017) scales: Scale Functions for Visualization. R package version 0.5.0

Wild C, Hoegh-Guldberg O, Naumann MS, Colombo-Pallotta MF, Ateweberhan M, Fitt WK, Iglesias-Prieto R, Palmer C, Bythell JC, Ortiz J-C (2011) Climate change impedes scleractinian corals as primary reef ecosystem engineers. Marine and Freshwater Research 62:205-215
Wilson J, Osenberg CW (2002) Experimental and observational patterns of density-dependent settlement and survival in the marine fish Gobiosoma. Oecologia 130:205-215

Wilson S, Graham N, Polunin NV (2007) Appraisal of visual assessments of habitat complexity and benthic composition on coral reefs. Marine Biology 151:1069-1076

Young G, Dey S, Rogers A, Exton D (2017) Cost and time-effective method for multi-scale measures of rugosity, fractal dimension, and vector dispersion from coral reef 3D models. PLoS ONE 12:e0175341

Youngbluth MJ (1968) Aspects of the ecology and ethology of the cleaning fish, Labroides phthirophagus Randall. Zeitschrift für Tierpsychologie 25:915-932

Publisher's Note Springer Nature remains neutral with regard to jurisdictional claims in published maps and institutional affiliations. 